\title{
Synthesis and characteristics of titanium silicalite TS-1, Ti-Beta and Ti-MWW catalysts
}

\author{
Agnieszka Wróblewska, Anna Fajdek, Eugeniusz Milchert \\ West Pomeranian University of Technology, Institute of Organic Chemical Technology, ul. Pułaskiego 10, Pl 70-322 \\ Szczecin, Poland, e-mail: agnieszka.wroblewska@ps.pl
}

\begin{abstract}
The synthesis methods of the following titanium-silicalite catalysts: TS-1, Ti-Beta and Ti-MWW were presented. The results of the analyses of the catalysts by XRD, SEM and IR, UV-vis methods were also shown. A brief description of the catalytic performances of these catalysts in the oxidation process of olefins, alkenes, alcohols and aromatic compounds was presented.
\end{abstract}

Keywords: TS-1, Ti-Beta, Ti-MWW, titanium-silicalite catalysts.

\section{INTRODUCTION}

One of the main challenges of modern industrial chemistry is the need to develop the alternative technologies of production that would be cleaner, safer and more environment- friendly. New processes should by more efficient with regard to the consumption of energy and raw materials and should produce a minimum amount of waste. In many cases a large-tonnage production is departed and replaced by a low-tonnage one. The application of heterogeneous catalysts is frequently advantageous, for example the molecular sieves of the redox type, where the oxygen was joined with a metal in an inorganic matrix. Molecular sieves of the redox type offer many advantages in comparison with the conventional oxidation catalysts. As opposed to the amorphous materials, the molecular sieves have uniform surroundings in the form of channels and holes with an appropriate shape and magnitude. The location of the active sites on the inner surface of the molecular sieves creates the possibility of the formation of shape-selective catalyst. Moreover, the dimension and a hydrophobic/hydrophilic character of the redox holes may be a method for the selection of an appropriate catalyst. Thus, the molecular sieves of the redox type can be identified with mineral enzymes. The first example of molecular sieves of the redox type was titanium silicalite TS-1, obtained by Enichem company ${ }^{1-5}$.

The TS- 1 catalyst has a three-dimensional channel system, which is a combination of the linear and zig-zag locations. This catalyst crystallizes in the orthorhombic system, and the crystallites have the size of $0.1-1.0 \mu \mathrm{m}$, whereas the pore size amounts $0.53 \times 0.56 \mathrm{~nm}^{6}$.

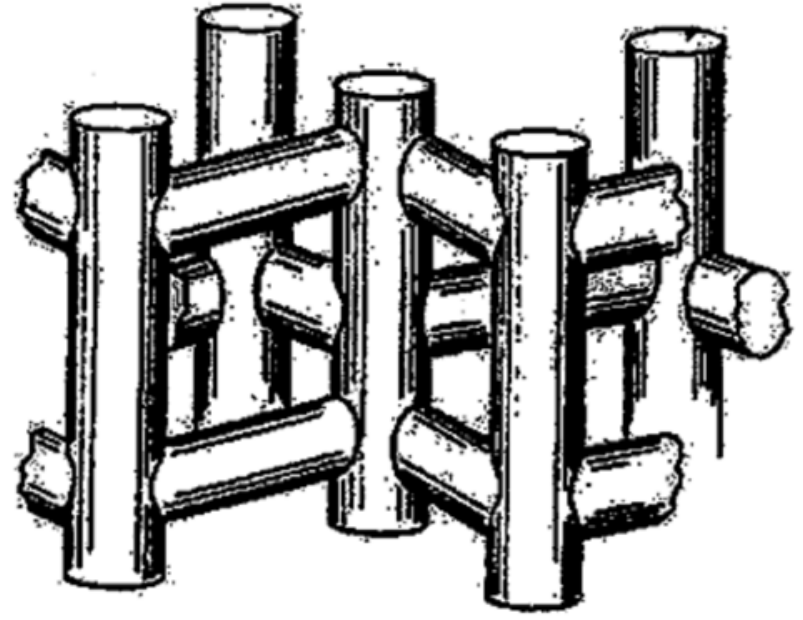

Figure 1. Channel system in TS-1 catalysts

The active site of this catalyst is $\mathrm{Ti}^{4+}$ incorporated into the silica structure. This structure is named as MFI. The pore system contains 10 -membered ring openings. The template used in the TS-1 synthesis is tetrapropylammonium hydroxide $(\mathrm{TPAOH})^{6-7}$.

The TS- 1 catalyst applications are connected with the oxidation reactions of alkanes, alkenes and aromatic hydrocarbons, with the help of hydrogen peroxide as oxidant and they proceed very often under mild conditions ${ }^{\mathbf{8}} \mathbf{9}$.

Using TS- 1 as the catalyst and aqueous hydrogen peroxide as the oxidizing agent, phenol is hydroxylated selectivity to dihydroxybenzenes (Figure 2). Only the ortho- and paraisomers, in the hydroxylation of phenol reaction are formed. The reason for the high $\mathrm{o}$ - and p-selectivity is the resonance

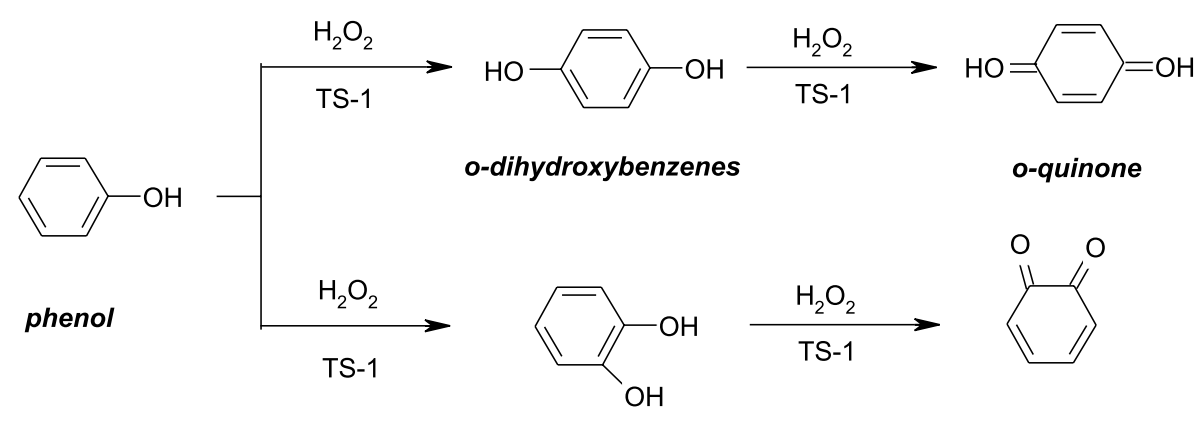


stabilization of the phenol molecule. The $\mathrm{OH}$ - group is a ring activator, it enhances the reactivity of the ring and favors electrophilic attack at $\mathrm{o}-$ and $\mathrm{p}$ - $\operatorname{sites}^{\mathbf{1 0}}$. In the restricted pore geometry of the TS-1 zeolite the formation of paradihydroxybenzene is highly favored. The p:o ratio, which is 0.5 in solution, could be enhanced up to the values of 2.911. In a slow consecutive step the dihydroxibenzenes are oxidized to the corresponding quinines. Such a process with relatively high phenol conversion employing TS-1 as a catalyst (Figure 2) was industrially realized by the Enichem company ${ }^{\mathbf{1 2}-13}$. This was the first industrial process in which TS-1 was applied.

Paraffins are chemically inert and strong oxidizing agents are required for their oxidation. However, with TS-1 and aqueous $\mathrm{H}_{2} \mathrm{O}_{2}$ saturated organic compounds can be selectively oxidized at the secondary and tertiary $\mathrm{C}$ atoms to the corresponding alcohols and subsequently to the ketons under relatively mild conditions. Thus, $n$-hexane can be selectively oxidized to a mixture of 2-hexanol, 3-hexanol and further to the corresponding ketones, according to the reaction pathways given in Figure 3. This reaction, which uses methanol as the solvent, was first reported independently by three groups: Clerici et al. ${ }^{\mathbf{1 4}}$, Tatsumi et al. ${ }^{\mathbf{1 5}}$ and Huybrechts et al. ${ }^{16}$.

The region-selectivity of the reaction found by various authors differs significantly. For n-hexane oxyfunctionalization, Clerici et al. reported the ratio between the products substituted on 2-3-position to be $2.6^{\mathbf{1 4}}$, whereas Huybrechts et. al. found this ratio to be around $1^{\mathbf{1 6}}$. The experiments by Clerici et al. were preformed at the temperature of $55^{\circ} \mathrm{C}$ and atmospheric pressure; Huybrechts et al. ran their experiments at $100^{\circ} \mathrm{C}$ in autoclaves. Due to the increase in temperature and pressure the oxidation of the $3 \mathrm{rd}$ carbon atoms is enhanced, and reduces the selectivity for the oxidation of the 2 nd carbon atom.

The selective oxidation of alcohols to carbonyl compounds using TS-1 and hydrogen peroxide also had been studied. Researches from Enichem were the first ones who reported the selective formation of carbonyl compounds (aldehydes and ketones) during the oxidation of the corresponding alcohols over the TS-1 catalyst. However, during the oxidation of primary alcohols, the aldehydes formed can undergo consecutive oxidation to carboxylic acids, which in turn can gives esters by reaction with the still available alcohol molecules. Thus, in order to obtain sufficient selectivity it is necessary to work with alcohol to $\mathrm{H}_{2} \mathrm{O}_{2}$ ratios significantly higher than one to avoid the oxidation of the formed aldehyde to an acid ${ }^{17}$.

Clerici et al. suggested two versions for the olefins oxidation mechanism over TS-1 (Fig. 4). The main point in this mechanism is the role of the solvent molecule in the process, which together with hydrogen peroxide is coordinated at the titanium center to form an extended Ti-hydroperoxo complex (1). In the first version of this mechanism the A substrate molecule reacts with the oxygen atom in second position $\left({ }^{2} \mathrm{O}\right)$. In the second version of the mechanism the substrate molecule reacts with the 1st oxygen atom, and the same products are formed as in the first version. However, this attack of the substrate seems to be disfavored on the basis of steric arguments, namely since the 2 nd position of oxygen atom (as in mechanism $\mathrm{A}$ ) is more accessible for substrate molecules because it is located more inside the zeolite channel. The 1st position of $\mathrm{O}$ (as in mechanism $\mathrm{B}$ ) is closer to the zeolite wall and consequently less accessible for the substrate molecules ${ }^{18}$.

Altogether, TS-1 is a versatile catalyst for selective oxidation reactions with hydrogen peroxide, and new reactions using this catalytic system, are continuously discovered. There are also selective oxidation experiments with other substrates in addition to the hydrocarbons and their oxygen (or nitrogen) containing derivatives, for example aniline ${ }^{\mathbf{1 9}}$.

Titanium-silicalite with a low content of aluminium - TiBeta, was prepared in the presence of TEAOH as a templating compound $^{\mathbf{2 0}}$. The catalyst structure is the same as in TS-1. However, the average pore size is larger $-0.8 \mathrm{~nm}$. The framework structure contains a channel system with 12memmbered ring openings. The framework structure of TiBeta catalyst is shown in Figure 5. It was concluded, that titanium performs the primary role in the stabilization of the structure of Beta zeolite. Simultaneously, titanium competes with aluminium in the incorporation into the zeolite structure ${ }^{19}$.

Catalyst Ti-Beta was active in the oxidation process of alkanes and alkenes. Van der Waal presented a good study on the epoxidation of linear alkenes. The catalytic epoxidation of linear alkenes, such as 1-hexene, 1-heptene, 1-octene, 2octene (mixture of cis and trans), trans-4-octene, 1-decene in acetonitrile at $70^{\circ} \mathrm{C}$, shows that Ti-Beta is highly active and selective for all the tested alkenes ${ }^{\mathbf{2 0}}$. The highest activity is observed for 1-hexene (93\% yield) and the lowest activity for 1-decene ( $81 \%$ yield); the longer the chains the lower the activity propably due to diffusion limitations.

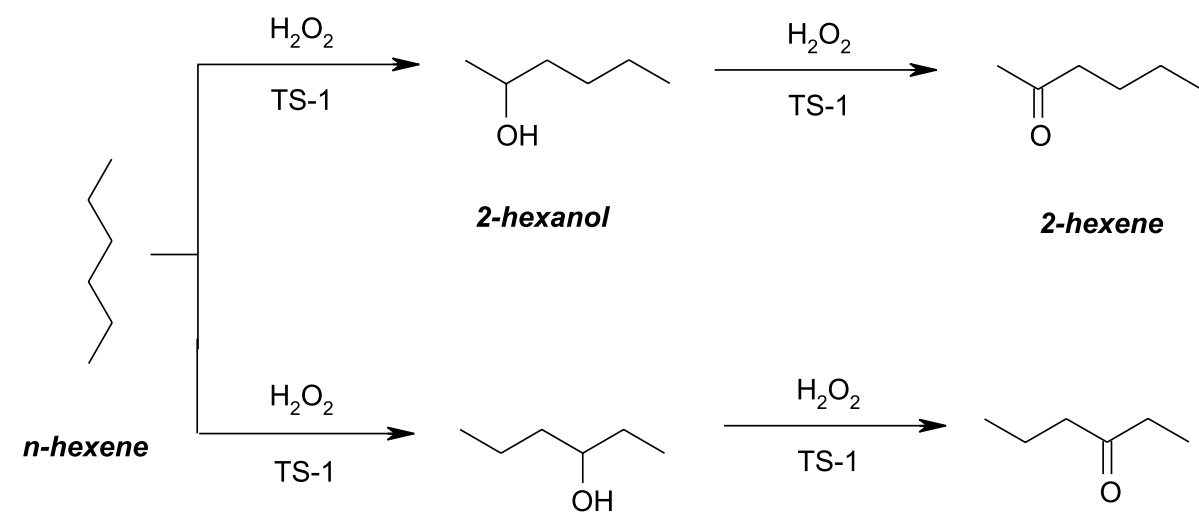




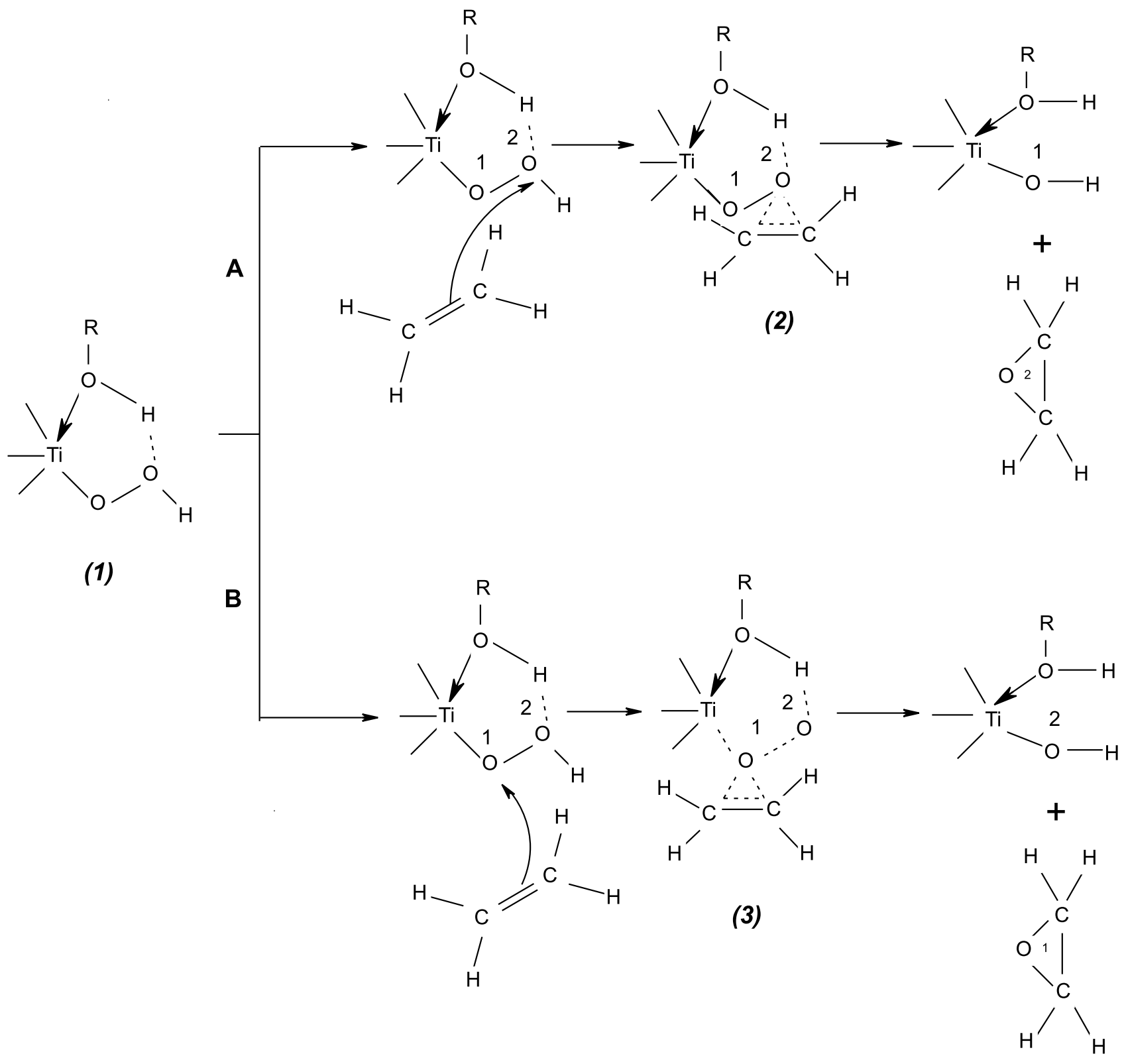

Figure 4. Two possible ways of oxidation of olefins suggested by Clerici et. al.

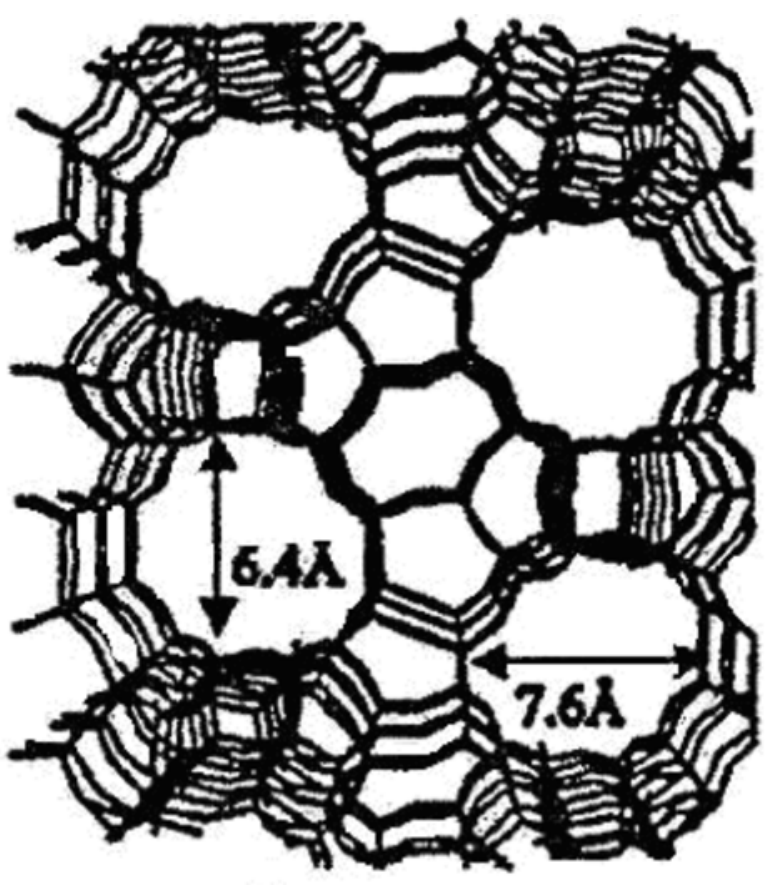

Figure 5. Channel system of Ti-Beta catalysts
To investigate the effect of the pore size of Ti-Beta zeolite van der Waal used as test reaction the epoxidation of norbornene (bicyclo[2.2.1]hept-2-ene) with hydrogen peroxide and methanol as the solvent ${ }^{20}$. The large pore size of the Ti-Beta allows moderately selective epoxidation of norbornene, about $27 \%$ of the product is norbornene epoxide. The lack of activity of TS-1 in the epoxidation of norbornene can be attributed to the small size of its pores. Norbornene molecules are too large to diffuse into the channels of this zeolite. With Ti-Beta the major by-products catalyzed by Bronsted acid sites is the diol (bicyclo[2.2.1] hept-2,3-diol) with minor amount of the glycol monomethyl ether' ${ }^{21}$.

Epoxidation of allylic compounds was also accomplished over Ti-Beta zeolite with hydrogen peroxide. These substrates have two reactive groups that can be oxidized - the double $\mathrm{C}=\mathrm{C}$ bond to an epoxide or a glycol, and the alcohol hydroxyl group to a carbonyl group. Therefore, allylic compounds are good models for an investigation of the influence of electronic effects of substituents on the products of the partial oxidation. Classically, the oxidation of allylic alcohols is realized by the Corey-Schmidt method; similarly to nor- 
<smiles>[R]C(=O)C([R])[R]</smiles>

Figure 6. Epoxidation of linear alkenes on Ti-Beta

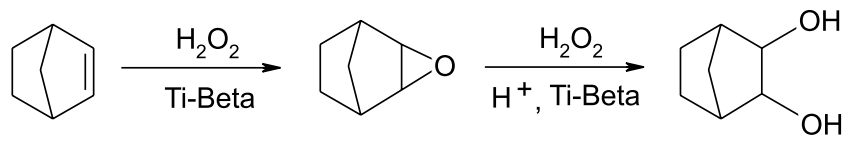

Figure 7. Oxidation of norbornene

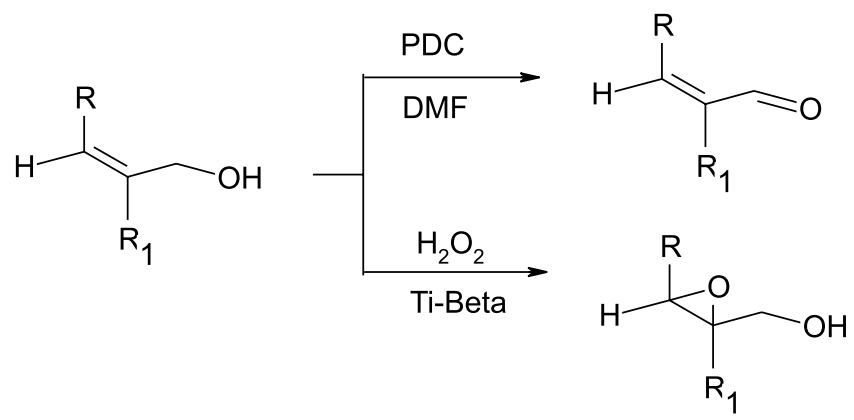

Figure 8. Partial oxidation of allylic alcohols. PDC dipyridinium dichromate, DMF - N,N dimethylformamide

mal primary alcohols they are oxidized to the corresponding aldehydes with yields higher than $80 \%$.

A novel zeolite with MWW topology, having a unique and unusual crystalline structure, is expected to serve as such a candidate for the preparation of Ti-containing catalysts that are both highly stable and accessible ${ }^{23}$. The MWW structure is constructed from a lamellar precursor undergoing dehydroxilation upon calcinations between the layered sheets. Besides two-dimensinal sinusoidal channels of 10-membered rings (MR) running throughout the structure parallel to the $a b$-plane, the MWW structure contains an independent channel system which is comprised of large supercages $0.7 \times 0.7$ $\times 1.8 \mathrm{~nm}$. The supercages turn to be pocket or cup moieties $0.7 \times 0.7 \mathrm{~nm}$ at the crystal exterior ${ }^{23}$. This may provide potential opportunities for a wide variety of applications in petrochemical and fine chemical industries ${ }^{24}$. Ti-MWW is a highly selective industrialized catalyst for benzene alkylation, and it is not only more active than TS- 1 and Ti-Beta in the liquid-phase epoxidation of linear alkenes with hydrogen peroxide, but also highly selective for the formation of epoxides $^{25}$.
In addition, this material also shows a unique feature of selective epoxidation of the trans-isomer in the oxidation of cis- and trans-2-hexenes ${ }^{26-27}$. Actually, the potential advantage to the MWW structure is expected from its interlayer supercages and side pockets, which could be very useful for catalyzing the reactions involving bulky molecules. The retention of the lamellar-like structure with expanded layer spacing after calcinations would be an alternative way to create the open reaction space in the disproportionation of toluene and in the alkylation of benzene ${ }^{24}$.

Ti-MWW catalyzes more actively the epoxidation of DAE to AGE and DGE (description in Fig. 11) with aqueous hydrogen peroxide than TS-1. Ti-MWW favors acetonitryle or acetone as a suitable solvent. Ti-MWW, which is stable enough to endure the Ti leaching, proves to a regeneratable catalyst for DAE epoxidation ${ }^{28}$.

Ti-MWW is capable of catalyzing the liquid-phase ammoximation of cycloheksanone to oxime at a conversion and selectivity $>99 \%$ in the presence of water under optimum conditions, and proves to be a promising catalyst for oxime synthesis. The catalytic behavior of Ti-MWW in

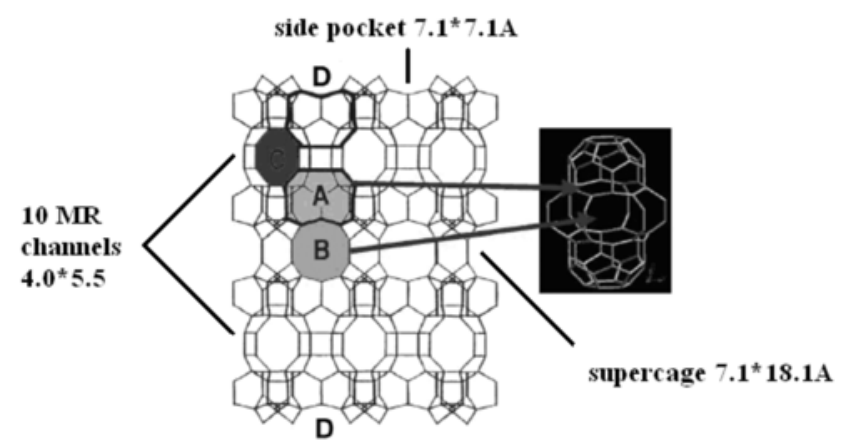

Figure 9. Schematic of Ti-MWW. It has unique structural features: 12-ring cavity (A), accessible through a 10-ring aperture (B), 10-ring channel system (C) and 12-ring surface pockets (D)

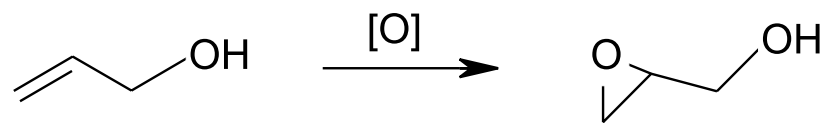

Figure 10. Epoxidation of allyl alcohol 


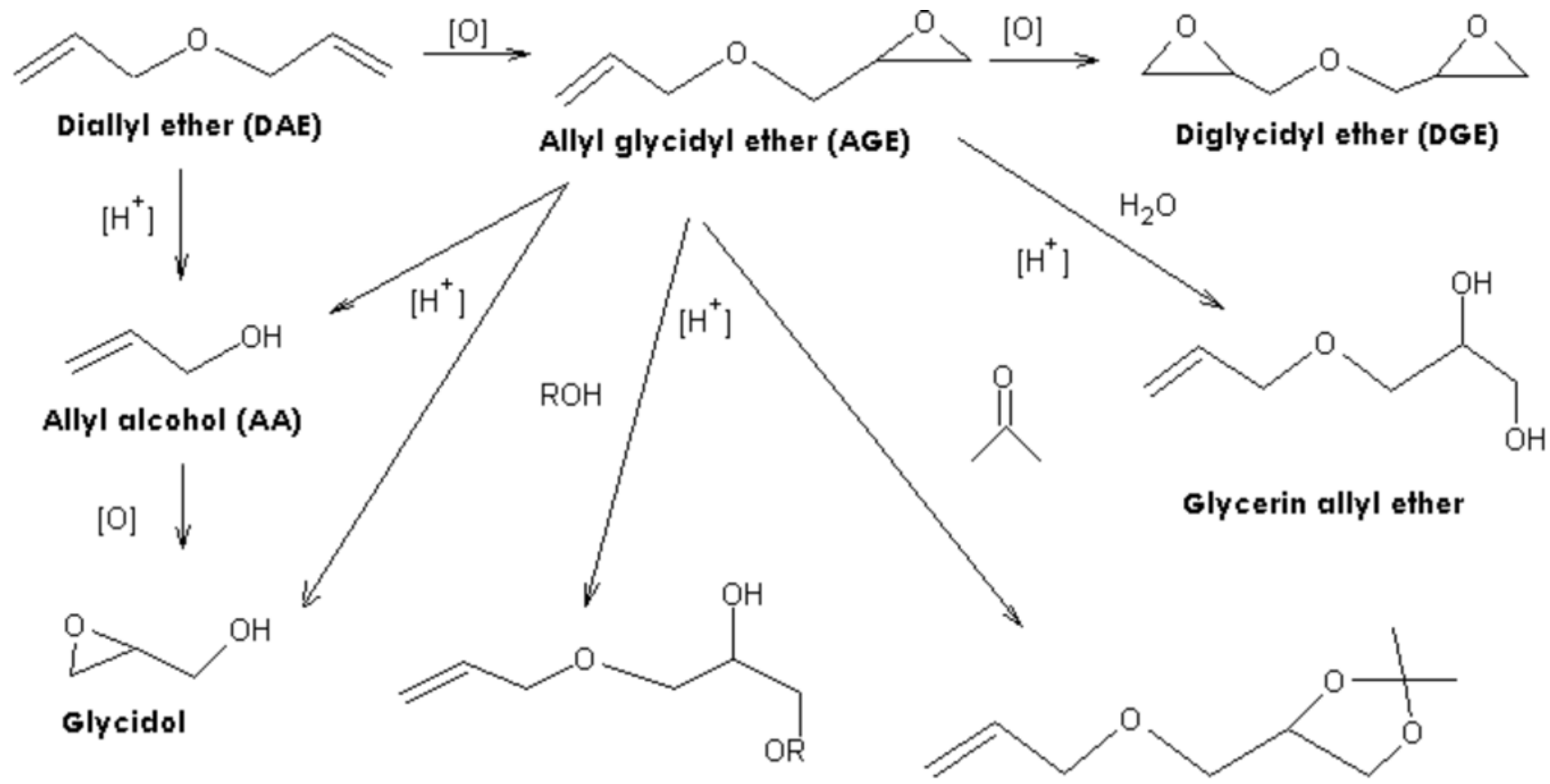

Solvolysis products

Figure 11. Reaction pathways in the epoxidation of diallyl ether with hydrogen peroxide

(A)

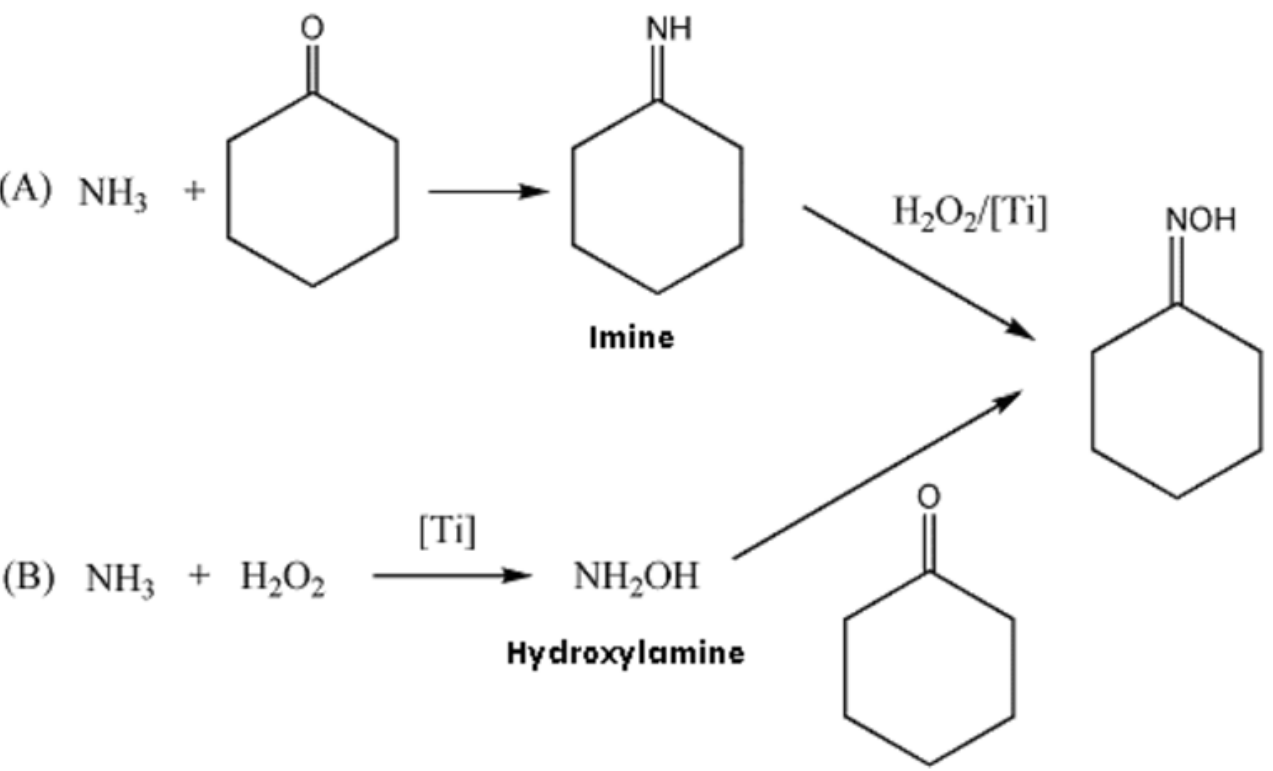

Figure 12. Possible ammoximation pathways

ammoximation depends greatly on the method used to add $\mathrm{H}_{2} \mathrm{O}_{2}$.

Ti-MWW shows high conversion of ketone to oxime only when $\mathrm{H}_{2} \mathrm{O}_{2}$ is added slowly into the reaction system. To achieve high conversion of ketone to oxime, the presence of free $\mathrm{H}_{2} \mathrm{O}_{2}$ and the extensive oxidation of hydroxylamine on the Ti species of Ti-MWW with extremely high oxidation ability must be avoided ${ }^{29}$.

\section{EXPERIMENTAL}

For the synthesis of titanium-silicalite catalysts the following compounds: tetraethyl o-silicate $\left(\mathrm{Si}(\mathrm{OEt})_{4}\right)$, tetrabutyl otitanate $\left(\mathrm{Ti}(\mathrm{OBu})_{4}\right)$, hexamethylenoimine $\left(\mathrm{HMI}, \mathrm{C}_{6} \mathrm{H}_{13} \mathrm{~N}\right)$, boric acid $\left(\mathrm{H}_{3} \mathrm{BO}_{3}\right)$, fumed silica (Cab-o-sil M5), tetrapropylammonium hydroxide (TPAOH), and tetraethylammonium hydroxide (TEAOH), were applied.

\section{Synthesis of titanium-silicalite catalyst TS-1}

The standard methods of TS- 1 titanium-silicalite catalyst syntheses described in the literature ${ }^{30-31}$ are performed according to the following procedure. An aqueous solution of tetrapropylammonium hydroxide (TPAOH, templating compound) was added to the mixture of tetraethyl o-silicate $\mathrm{Si}(\mathrm{OEt})_{4}$, isopropyl alcohol and water. Subsequently, a solution of tetrabutyl o-titanate $\mathrm{Ti}(\mathrm{OBU})_{4}$ in dry isopropyl alcohol was added under vigorous mixing. The titanium-silicalite sol was obtained as a result of the oligomerization of monomeric $\mathrm{Si}(\mathrm{OH})_{4}$ and simultaneous inclusion of titanium ions. The resulting clear liquid was heated to approximately $60^{\circ} \mathrm{C}$ and kept at this temperature for 1 hour. An queous solution of templating compound was then added in order to completely hydrolyze $\mathrm{Si}(\mathrm{OH})_{4}$. The resulting sol (clear solution) was heated to $75-80^{\circ} \mathrm{C}$ and maintained at this temperature for 8 hours. The titanium-silicalite gel was 


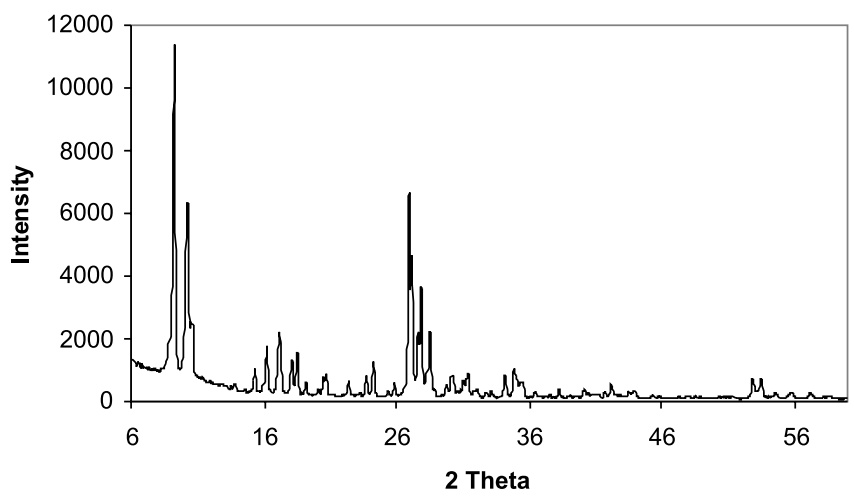

Figure 13. XRD pattern of the obtained TS-1 catalyst

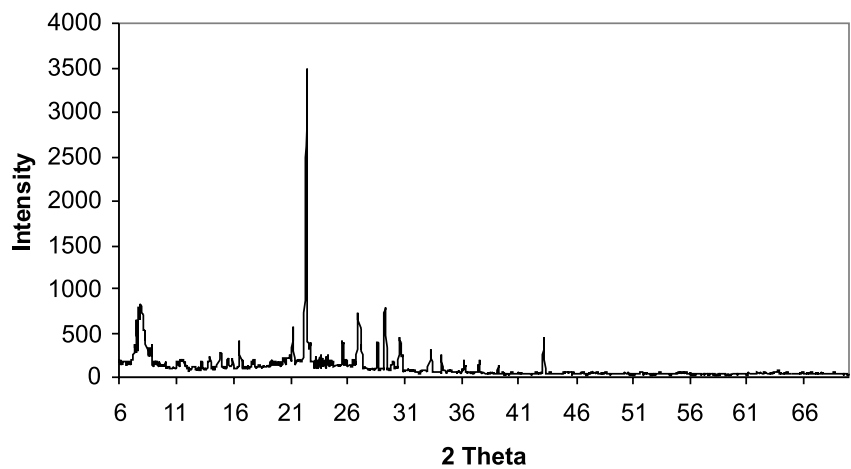

Figure 14. XRD pattern of the obtained Ti-Beta catalyst

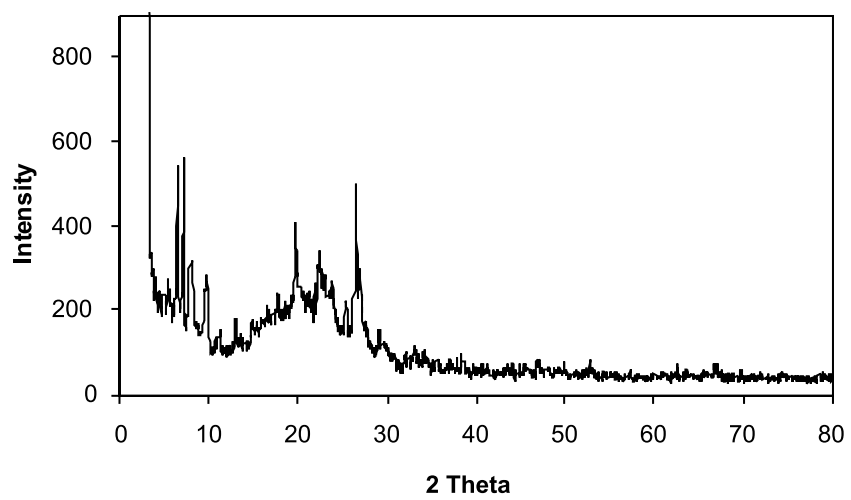

Figure 15. XRD pattern of the obtained Ti-MWW catalyst

obtained as a result of the coagulation. Gel for crystallization was transferred into a Teflon-lined autoclave (Berghof) and the crystallization was carried out for $8-30$ days at $170^{\circ} \mathrm{C}$. The catalyst crystals were washed with deionized water and dried at $119^{\circ} \mathrm{C}$ for 8 hours. The prepared catalyst was then calcinated at $500^{\circ} \mathrm{C}$ for 16 hours. The obtained catalyst can be activated by washing with $10 \%$ aqueous solution of ammonium acetate.

\section{Synthesis of titanium-silicalite catalyst Ti-Beta}

Ti-Beta catalyst was obtained by the methanol of Camblor et al. $^{32}$. A glass reactor equipped with stirrer reflux condenser, dropper and thermometer was charged with tetraethyl o-silicate, dry isopropyl alcohol and deionised water. Tetraethyl ammonium hydroxide - a templating compound was then added dropwise and then a previously prepared solution of tetrabutyl o-titanium in a dry isopropyl alcohol. After vigorously stirred for $1 \mathrm{~h}$ tetraethyl ammonium hydroxide and sodium aluminate diluted with deionised water was added drop by drop to obtain a gel. Subsequently, sodium hydroxide and potassium chloride were introduced. The content was stirred for 8 hours. The prepared titanium-
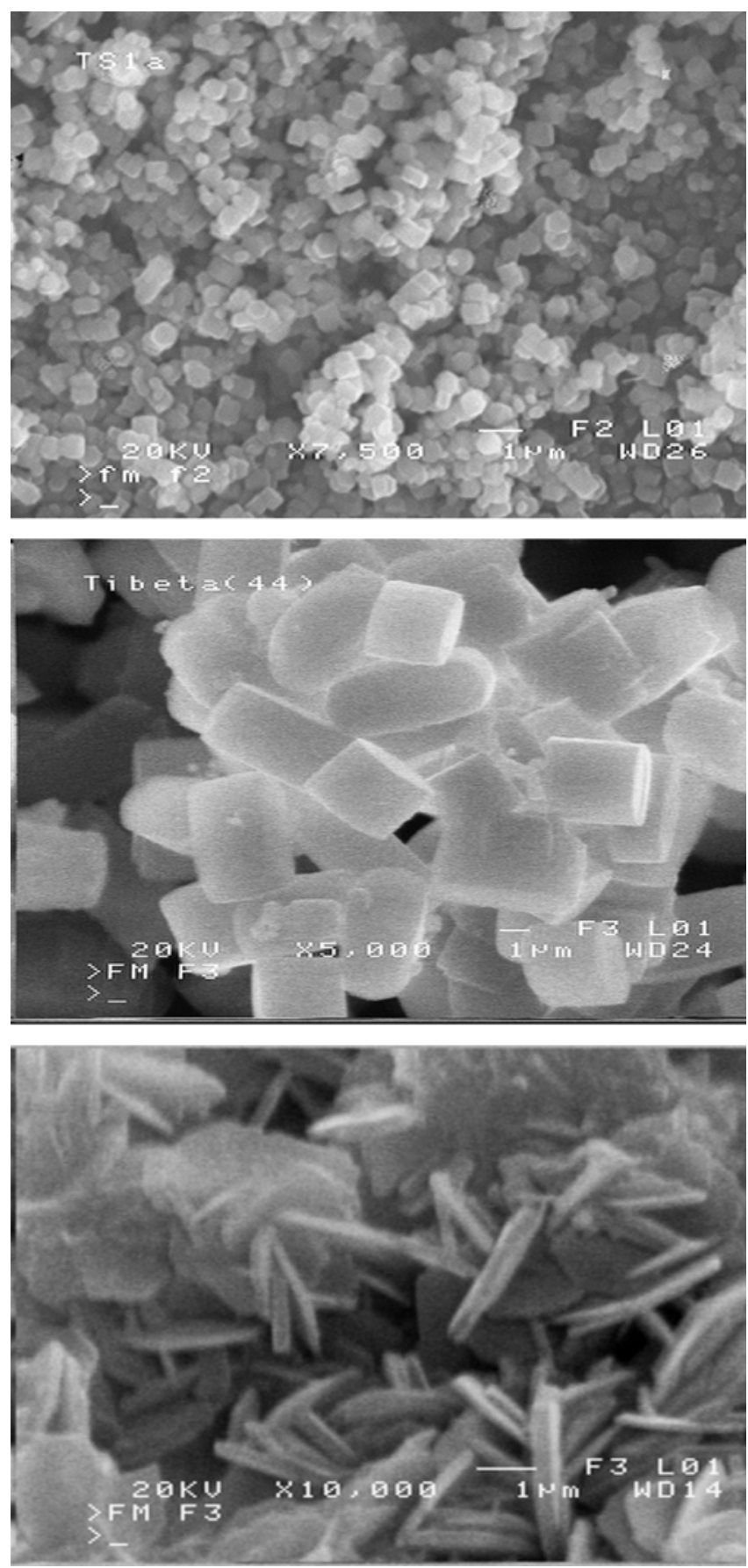

Figure 16. Scanning electron micrographs of the obtained TS-1, Ti-Beta and Ti-MWW catalysts (after calcination)

alumino-silicate gel was transferred into the Teflon-lined autoclave (Berghof). The crystallization was performed at $140^{\circ} \mathrm{C}$ for 7 days under an autogenic pressure. The separated crystallites were calcined for 24 hours in an oven at the temperature of $600^{\circ} \mathrm{C}$.

\section{Synthesis of titanium-silicalite catalyst Ti-MWW}

The Ti-MWW catalyst was synthesized by the method of $\mathrm{Wu}$ et $\mathrm{al} .{ }^{33}$ : hexametylenoimine (HMI) was dissolved in deionized water at room temperature. This solution was divided into two equal parts, to one tetrabutyl o-titanate $\mathrm{Ti}(\mathrm{OBu})_{4}$ was added, and to the other boric acid was added under vigorous stirring. The stirring was maintained for 30 min to hydrolyze tetrabutyl o-titanate. Fumed silica (Cab-osil M5) was divided into two equal parts, which were added gradually to the solutions containing $\mathrm{Ti}$ and $\mathrm{B}$, respectively. A further stirring for 1 hour was allowed to form two homo- 


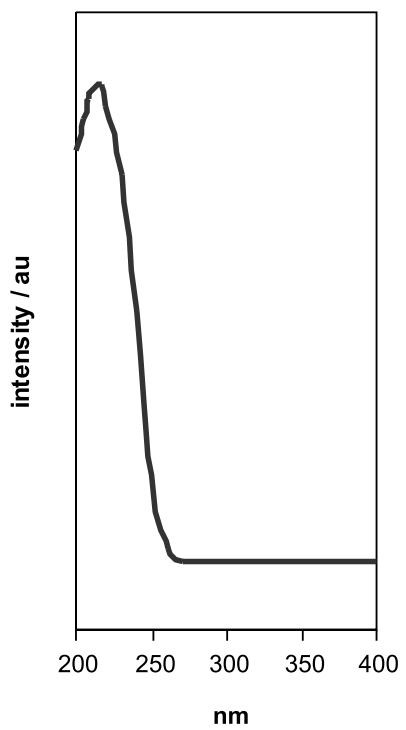

Figure 17. UV-vis spectrum of the obtained TS-1 catalyst

geneous gels. The gels were then mixed together and stirred for 1.5 hours to obtain a gel. The resulting gel was transformed into a Teflon-lined autoclave (Berghof) and heated with a stirring rate of $100 \mathrm{rpm}$ at $170^{\circ} \mathrm{C}(443 \mathrm{~K})$ for 14 days. After cooling, the solid product was filtered off and washed with deionized water to $\mathrm{pH}<9$. The product was then dried at $50^{\circ} \mathrm{C}(323 \mathrm{~K})$ for 1 day. To remove $\mathrm{B}$ and extra-framework Ti species, an acid treatment with the $6 \mathrm{M} \mathrm{HNO}_{3}$ solution was carried out at $100^{\circ} \mathrm{C}(373 \mathrm{~K})$ for 20 hours at a solidliquid ratio of $1 \mathrm{~g}$ to $20 \mathrm{ml}$. After the acid-treatment the sample was then calcined at $530^{\circ} \mathrm{C}(803 \mathrm{~K})$ to burn off any residual organic species.

The syntheses of the above-mentioned catalysts were conducted by means of the following methods: XRD (the X-ray diffraction spectroscopy, X'Pert PRO Philips diffractometer using $\mathrm{CuK} \alpha$ radiation) - this method permits qualifying the type of crystalline structure of the catalyst as well as confirming the presence of anataze, IR (the spectroscopy in infra-red radiation, Shimadzu FTIR-8100 spectrometer using $\mathrm{KBr}$ pellet technique) - it confirms the presence of titanium in the studied sample, SEM (the scanning electron microscopy, JOEL JSM-6100 instrument) - it permits to quality, the size and shape of the particles of catalysts, UV-VIS (the spectroscopy in ultra-violet and blank space visible) - it confirms the incorporation of titanium into the structure of the catalyst.

\section{RESULTS}

The crystalline structure of the samples was confirmed by $\mathrm{X}$-ray powder diffraction spectroscopy (XRD). The diffraction pattern of the TS- 1 catalyst was the same as in literature $^{30}$ - Fig. 13. The XRD pattern of Ti-Beta was also close to the literature data ${ }^{33}$ - Fig. 14 and 15.

The morphology of the crystals was determined on the basis of the SEM micrographs. In the TS- 1 catalyst, they were uniform orthorhombic crystallites with a size in the range of $0.1-0.3 \mu \mathrm{m}$. Cubicoid crystallites with a length $4-8 \mu \mathrm{m}$ and width $1-2 \mu \mathrm{m}$ were in Ti-Beta catalyst. TiMWW samples exhibited the presence of hexagonal plates, approximate with size $0.3 \times 3 \mu \mathrm{m}$. This is consistent with what has been reported for the aluminosilicate MCM-22, which is also prepared using hexamethylenoimine ${ }^{33}$.
The IR spectra of the samples showed the presence of the absorption band $\sim 960 \mathrm{~cm}^{-1}$. The UV-vis spectrums for the titanium-silicalite catalysts showed a characteristic band at $220 \mathrm{~nm}$, which confirms the incorporation of titanium into the crystalline structure of silica.

\section{CONCLUSIONS}

The presented methods of syntheses of titanium-silicalite catalysts: TS-1, Ti-Beta and Ti-MWW allowed to obtain these catalyst. The instrumental analyses confirm obtaining the titanium silicalite catalysts. In the next steps of the investigations the titanium-silicalite catalysts were applied in epoxidation processes to confirm their catalytic activity. The preliminary studies showed that theTi-MWW catalyst was active in the process of allylic compound epoxidation.

\section{LITERATURE CITED}

1. Sheldon, R. (1996). Selective catalytic synthesis of fine chemicals: opportunities and trends. J. Mol. Catal. A: Chemical 107(1 - 3), 75 - 83. DOI: 10.1016/1381-1169(95)00229-4.

2. Sheldon, R., Arends, I. \& Dijksman, A. (2000). New developments in catalytic alcohol oxidations for fine chemicals synthesis. Catal. Today 57(1 - 3), 157 - 166. DOI: 10,1016/ S0920-5861(99)00317-X.

3. Blaser, H. \& Studer, M. (1999). The role of catalysis for the clean production of fine chemicals. Appl. Catal.189, 191 - 204. PII: S0926-860X(99)00276-8.

4. Mills, P. \& Chaudhari, R. (1997). Multiphase catalytic reactor engineering and design for pharmaceuticals. Cat. Today 37(4), 367 - 404. DOI: 10,1016/ S0920-5861(97)00028$\mathrm{X}$.

5. Blaser, H. (2000). Heterogeneous catalysis for fine chemicals production. Cat. Today 60(1 - 3), $161-165$. DOI: 10,1016/S0920-5861(00)00332-1.

6. Millini, R., Massaro, E., Perego, G. \& Bellussi, G. (1992). Framework composition of titanium silicalite 1. J. Catal. 137(2), 497 - 503.

7. Wróblewska, A. \& Milchert, E. (2002). Synthesis of titanium-silicalite catalysts. Pol. J. App.Chem. 46(3 - 4), 151 -175 .

8. Khouw, C., Dartt, C., Labinger, J. \& Davis, M. (1994). Studies on the catalytic oxidation of alkanes and alkenes by titanium silicalites. J. Catal. 149, $195-205$.

9. Notari, B. (1987). Innovation in Zeolite Material Scienece. Stud. Surf. Sci. Catal. 37, 413.

10. Hauptman, S. (1985). Organische Chemie. Leibziger: VEB deutscher Verlag für Grundstoffindustrie.

11. Koch, M., Wark, M. \& Schulz-Ekloff, G. (1999). Report to Bayer $A G$. Germany : University of Bremen.

12. Kooyman, P. (1993). A Study On Titanium-Silicalite-1 And Related Systems. Delft: Technische Universiteit.

13. Notari, B. (1988). Innovation In Zeolite Materials Science. 37, 413.

14. Clerici, M. (1991). Oxidation of saturated hydrocarbons with hydrogen peroxide, catalyzed by titanium silicalite. Appl. Catal. 68(1 - 2), 249 - 261.

15. Tatsumi, T., Nakamura, M., Negeshi, S. \& Tominaga, H (1990). Shape-selective oxidation of alkenes with hydrogen peroxide catalyzed by titanosilicalite. J. Chem. Soc., Chem. Commun. 476 - 477.

16. Huybrechts, D., Bruyker, L. \& Jacobs, P. (1990). Oxyfunctionalization of alkenes with hydrogen peroxide on titanium silicalite. Nature 345, 240.

17. Romano, U., Esposito, A., Maspero, F., Neri, F. \& Clerici, M. (1990). New Developments In Selective Oxidation. Stud. Surf. Sci. Catal. 55, 33. 
18. Clerici, M. \& Ingllina, P. (1993). Epoxidation of lower olefins with hydrogen peroxide and titanium silicalite. $J$. Catal. 140, 71.

19. Goutier, S. \& Tuel, A. (1994). Oxidation of aniline over TS-1, the titanium substituted silicalite -1. Appl. Catal. A 118(2), 173 - 186.

20. Van der Waal J. (1998). Prof. Thesis Univ. Delft, The Niderlandy.

21. Van der Waal, J., Rigutto, M. \& Van Bekkum, H. (1997). Zeolite titanium beta as a selective catalyst in the epoxidation of bulky alkenes. Appl. Catal. A 167(2), 331 342. DOI: $10.1016 / \mathrm{S} 0926-860 \mathrm{X}(97) 00323-2$.

22. Corey, E. \& Schmidt, G. (1979). Useful procedures for the oxidation of alcohols involving pyridinium dichromate in aprotic media. Tetrahedron Lett. 5, 399 - 402.

23. Wu, P., Tatsumi, T., Komatsu, T. \& Yashima, T. (2001). A novel titano-silicalite with MWW structure: I. Hydrothermal synthesis, elimination of extraframework titanium, and characterizations. J. Phys. Chem. B 105(15), 2897 - 2905. DOI: $10.1021 / \mathrm{jp} 002816 \mathrm{~S}$.

24. Degnan, T. (2003). The implications of the fundamentals of shape selectivity for the development of catalysts for the petroleum and petrochemical industries. J. Catal. 216(12), 32 - 46. DOI: 10.1016/S0021-9517(02)00105-7.

25. Fan, W., Wu, P., Namba, S. \& Tatsumi, T. (2006). Synthesis and catalytic properties of a new titanosilicate molecular sieve with the structure analogous to MWW-type lamellar precursor. J. Catal. 243(1), 183 - 191. DOI: 10.1016/ jat.2006.07.003.

26. Wu, P., Tatsumi, T., Komatu, T. \& Yashima, T. (2002). A novel titanosilicate with MWW structure: II. Catalytic properties In The selective oxidation of alkenes. J. Catal. 202(2), 245 - 255. DOI: 10.1006/jat.2001.3278.

27. Wu, P. \& Tatsumi, T. (2002). Preparation of B-free TiMWW through reversible structural conversion. Chem. Commun. 1026 - 1027. DOI: 10.1039/b201170k.

28. Wu, P., Liu, Y., He, M. \& Tatsumi, T. (2004). A novel titanosilicalite with MWW structure. Catalytic properties In selective epoxidation of diallyl ether with hydrogen peroxide. J. Catal. 228(1), 183 - 191. DOI: 10.1016/jat.2004.09.001.

29. Song, F., Liu, Y., Wu, H. \& He, M. (2006). A novel titanosilicate with MWW structure: Highly effective liquidphase ammoximation of cycloheksanone. J. Catal. 237(2), 359 - 367. DOI: 10.1016/j.jcat.2005.11.018.

30. Vayssilov, G. (1997). Structural and physicochemical features of titanium siliclites. Catal. Rev. 39, 209.

31. Saxton, R. (1999). Crystalline microporous titanium silicalites. Top. Catal. 9(1 - 2), 43 - 57. DOI: 10.1023/ A:1019102320274.

32. Camblor, M., Corma, A., Martinez, A. \& Perez-Pariente, J. (1992). Synthesis of titaniumsilicoaluminate isomorphous to zeolite beta and its application as a catalyst for the selective oxidation of large organic molecules. J. Chem. Soc. 8 , $589-590$.

33. Wu, P., Tatsumi, T., Komatsu, T. \& Yashima, T. (2001). A novel titanosilicate with MWW structure. I. Hydrothermal synthesis, elimination of extraframework titanium, and characterizations. J.Phys. Chem. B 105(15), 2897 - 2905. DOI: 10.1021/jp002816s. 